[10] Grell'man, V., Seydler, S.; Malkin, A. Ya. (Ed.) (2010). Ispytaniya plastmass. Moscow: Nauchnye osnovy i tehnologii, 720.

[11] Shah, V.; Malkin, A. Ya. (Ed.) (2009). Spravochnoe rukovodstvo po ispytaniyam plastmass i analizu prichin ih razrusheniya. Moscow: Nauchnye osnovy i tehnologii, 736.

[12] Strel'nikov, V. P. (2007). Parametricheskaya DM raspredeleniya. Matematichekie mashiny i sistemy, 2, 117-124.

\title{
ENHANCING EFFICIENCY OF USING ENERGY RESOURCES IN HEAT SUPPLY SYSTEMS OF BUILDINGS WITH VARIABLE OPERATION MODE
}

\author{
Oleksandr Klymchuk \\ aaklymchuk@gmail.com \\ Alla Denysova ${ }^{1}$ \\ alladenysova@gmail.com \\ Gennadiy Balasanian \\ balasanyan@opu.ua \\ Lidiia Ivanova \\ leesoul18@gmail.com \\ Olena Bodiul \\ Department of Information Technologies and Cybersecurity \\ Odessa National Academy of Food Technologies \\ 112 Kanatna str., Odessa, Ukraine, 65039 \\ bodyulolena@ukr.net \\ ${ }^{1}$ Department of Thermal Powel Plants and Energy Saving Technologies \\ Odessa National Polytechnic University \\ 1 Shevchenka ave., Odessa, Ukraine, 65044
}

\begin{abstract}
As a research result, characteristic indicators of the efficiency of using various heat sources in combined heat supply systems were determined. During the study, various schemes for integrating heat accumulators in heat supply systems were considered. Water was used as a battery, which also acts as a coolant. Mathematical modeling of processes in combined heat supply systems using intermittent heating is carried out. The characteristic operating modes of the elements of heat supply systems that take into account the operating modes of heat consumers are determined. Mathematical modeling was carried out using a software package that allows to obtain the distribution of heat power of the heat supply system by its main elements and its characteristic operation modes. According to the research results, a coefficient of thermal power reduction and a coefficient of efficiency of using the heat accumulator volume were proposed. These coefficients allow to evaluate the efficiency of heat sources and the efficiency of using the volume of the heat storage tank. Based on the obtained data, the task was set to optimize the daily load of the heat source, taking into account the installation of the storage tank.

The research results can be used for the reconstruction of heat supply systems of buildings with a two-period operation mode (operation duty) using both traditional and renewable heat sources. This will significantly increase the efficiency of the use of elements of the heat supply system, even out the daily heat generation schedule and increase the service life of the main equipment.
\end{abstract}

Keywords: heat supply system, heat accumulator, intermittent heating, renewable energy sources, building operation modes. 


\section{Introduction}

Improving the efficiency of heat supply systems is associated with a number of factors: thermal modernization of buildings, the use of ventilation systems with heat recovery, the use of renewable energy sources, etc. [1]. A separate positive factor is the use of an alternating heat supply mode for public buildings (educational buildings, administrative buildings, industrial buildings, etc.) [2], since this is a huge potential for energy conservation. However, there are a number of circumstances that significantly affect the effectiveness of intermittent heating in these types of buildings: lack of thermal modernization, high inertia of the heating system, lack of source power for forced room heating [3]. The latter factor especially affects the efficiency of intermittent heating and leads to climatic restrictions on the use of variable heat supply modes.

The analysis of literature data shows that, depending on the temperature of the outside air, the indoor heating mode can be implemented in two ways:

- by maintaining maximum power [4];

- by maintaining a fixed moment of switching on the heat source [5].

In the first case, the variable parameter is the time instant that corresponds to the beginning of the heating mode [6], when there is no reserve of thermal power at low outdoor temperatures $[7,8]$. In this case, an important factor is the length of the on-time heating period. The duration of the last period depends on the outdoor temperature and becomes equal to zero at the outdoor temperature, which is equal to the design temperature for heating systems.

In the second case, the peak power of the heat supply source is a variable parameter $[9,10]$. This case assumes the presence of a power reserve and can be used in existing systems at outdoor temperatures significantly higher than the design temperature for heating systems.

At the same time, the task of reducing the operating time of the heat source remains relevant. This problem can usually be solved by:

- increase in the nominal power of the heat supply source, which in turn leads to an increase in the capital costs of the system, and also leads to an increase in the uneven operation of the source in the nominal mode;

- use of heat accumulators in the heat supply system, for the accumulation of heat energy during the non-operation period due to the presence of unused capacities of the heat source.

The latter option involves a significant reduction in capital costs for the reconstruction of the heat supply system, allows to align the schedule of heat sources, has a positive effect on their efficiency and service life [11].

As a rule, heat supply systems use water heat accumulators, less commonly, solid state batteries [12]. The main advantage of water batteries is that the heat-accumulating substance can simultaneously be a coolant. However, there is a main drawback - the maximum temperature in the battery, as a rule, does not exceed $90^{\circ} \mathrm{C}$.

The use of heat accumulators also positively affects the coordination of the hydraulic modes of heat generators and consumers [13, 14].

However, there is uncertainty in determining the specific volume of heat accumulators, which depends on the inertia of the heat supply object, the operating conditions of the building, and climatic conditions.

The aim of research is to increase the efficiency of heat supply systems when using intermittent heating due to the use of heat accumulators based on liquid materials.

To achieve this aim it is necessary to solve the following tasks:

- to conduct modeling of the operation of heat supply systems for public buildings using the example of the educational building;

- to determine the dependence of the specific volume of the heat accumulator on the design power of the generator;

- to develop recommendations for the implementation of the proposed solutions in existing heat supply systems.

The scientific novelty of the study is that a mathematical model of the dynamics of thermal processes in the system is proposed that takes into account operating modes, the level of thermal modernization of buildings, and also provides for the rational use of renewable energy sources 
when changing climatic conditions. The classification of intermittent heating modes has also been performed.

\section{Materials and methods of research}

Modeling of processes in the heat supply system with renewable heat sources (heat pump, pellet boiler) using the example of the educational building (Fig. 1) is based on the use of intermittent heating. The pellet boiler is taken as an example as a source using high quality renewable biofuels. Other types of boilers can also be considered.

Intermittent heating is determined by the schedule of the academic building and consists of the following steps:

- heating (forced heating mode) before the start of the operation day;

- operation (maintenance mode required by the norms of the parameters in the room);

- cooling (shutdown mode of heat sources);

- duty (if it is necessary to maintain indoor temperature not lower than $12{ }^{\circ} \mathrm{C}$ ).

The operating mode is determined based on the operating conditions of the case from 8-00 to $16-00$ hours.

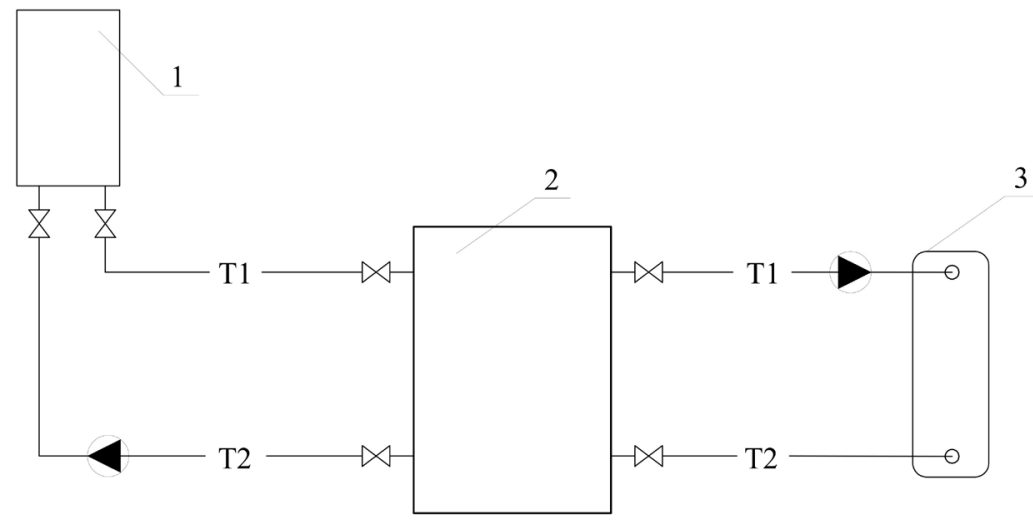

Fig. 1. Schematic diagram of the heat supply system of the educational building: 1 - heat source; 2 - heat accumulator; 3 - heat consumer.

The modeling of the dynamic properties of the building and the heating system is based on a system of differential equations and corresponding boundary conditions [15]. To solve the problem, let's use the MS Excel application package, which allowed to compactly program the calculation methodology and perform multidimensional optimization, taking into account the constraints and boundary conditions in the system.

The criterion for optimizing the load conditions of the combined heat supply system, which operates in intermittent heating mode, where the specified temperature mode is maintained, is the total daily heat consumption from the pellet boiler and heat pump $\sum_{i=0}^{23} Q_{i}$.

The equation for determining the optimal daily load mode of the heat source, when the objective function is minimal, has the form:

$$
\sum_{i=0}^{23} Q_{i}=\sum_{i=0}^{23}\left(Q_{i}^{P B}+Q_{i}^{H P}\right)
$$

where $i$ - the time of day, h; $Q_{i}^{P B}$ - hourly heat output of the pellet boiler, $\mathrm{kW} ; Q_{i}^{H P}$ - hourly heat output of the heat pump, kW.

From a mathematical point of view, the optimization problem can be considered as the problem of finding the extremum of the function of many variables (24 variables each are hourly average heat loads $Q_{i}^{P B}, Q_{i}^{H P} i=\overline{0.23}$, respectively), taking into account the restrictions and boundary conditions imposed on the optimized system. 
Given the nature of the relationship between the variables, the optimization problem belongs to the class of nonlinear programming problems and can be written in general form:

$$
\left\{\begin{array}{l}
\sum_{i=0}^{23} Q_{i}=\sum_{i=0}^{23}\left(Q_{i}^{P B}+Q_{i}^{H P}\right) \rightarrow \min \\
\left\{\begin{array}{l}
Q_{i \min } \leq Q_{i}^{P B} \leq Q_{i \max } \\
Q_{i \min }^{H P} \leq Q_{i}^{H P} \leq Q_{i \max }^{H P} \\
i=\overline{0.23}
\end{array}\right.
\end{array}\right.
$$

As a result of solving the problem of optimizing the load mode of the heat generator, it is possible to obtain daily schedules of the heat loads of the boiler and heat pump, ensuring a minimum of heat consumption, as well as a daily schedule of changes in room temperature, for this it is necessary to perform numerical simulation.

A liquid heat accumulator (HA) is the second component of a combined heat supply system.

HA has the following characteristics:

- volume $V$, which is a function of the heat source $A_{s c}$;

- form factor F;

- heat loss coefficient $k_{H A}$.

Let's assume that at an arbitrary instant of time t, the temperature of the coolant $T_{s}$ will be constant over the HA entire volume.

The thermal balance of liquid HA in general:

$$
E_{a}-E_{r}=E_{a c}
$$

where $E_{a}$ - added heat, $\mathrm{J} ; E_{r}$ - rejected heat, $\mathrm{J} ; E_{a c}$ - accumulated heat, J.

The heat balance equation for a liquid accumulator of a combined heat supply system [16]:

$$
V_{B} \cdot c_{p} \cdot p_{B} \cdot\left(\mathrm{d} T_{B}(t) / \mathrm{d} t\right)=Q_{\text {in }}(t)-Q_{\text {out }}(t)-Q_{l}(t)
$$

where $Q_{\text {in }}(t), Q_{\text {out }}(t)$ - respectively, the heat flux at the input and output of the HA, W; $Q_{l}(t)$ - heat loss to the environment, W.

According to the first law of thermodynamics for the supplied and withdrawn energy of an open system, the basic equation of energy storage in differential form has the form [17]:

$$
\left(u+p v+g H+c^{2} / 2\right)_{a} \cdot \mathrm{d} m_{r}+\mathrm{d} Q-\left(u+p v+g H+c^{2} / 2\right)_{a} \cdot \mathrm{d} m_{r}-\mathrm{d} W=\mathrm{d}\left(u+g H+c^{2} / 2\right)_{a c} \cdot \mathrm{d} m_{a c},
$$

where $m_{a c}$ - the mass of the operation medium, kg; $u$ - internal energy, $\mathrm{J} / \mathrm{kg} ; p$ - pressure, Pa; $v-$ specific volume, $\mathrm{m}^{3} / \mathrm{kg} ; g$ - acceleration of gravity, $\mathrm{m} / \mathrm{s}^{2} ; H$ - height, $\mathrm{m} ; g H--$ specific potential energy, $\mathrm{J} / \mathrm{kg} ; c$ - flow velocity, $\mathrm{m} / \mathrm{s} ; c^{2} / 2$ - specific kinetic energy, $\mathrm{J} / \mathrm{kg} ; \mathrm{d} Q$ - heat supplied to the system, $\mathrm{J} ; \mathrm{d} W$ - system operation, $\mathrm{J}$.

HA thermal losses into the environment are [18]:

$$
Q_{n}(t)=k_{H A} \cdot V^{2 / 3} \cdot F \cdot\left(T_{s}(t)-T_{e}\right)
$$

For the numerical simulation of the heat supply object, the educational building has been selected, which has the following characteristics: 4 floors, the total area of the premises is $1500 \mathrm{~m}^{2}$; volume of premises $-4800 \mathrm{~m}^{3}$. The energy efficiency level according to Ukrainian standards is class C. A multilevel thermal modernization of the building has been completed: thermal insulation of the external walls (100 mm of extruded polystyrene foam); replacement of windows with energy-efficient (thermal resistance of at least 0.8 ); shielding of the inner surfaces of the outer walls with special thermal insulation, the installation of supply and exhaust ventilation with recovery (with the installation of $\mathrm{CO}_{2}$ sensors on the premises). 
An analysis of the results of numerical simulation of the operating modes of the combined heat supply system using heat storage (Fig. 2) shows a significant advantage of the heat accumulator (HA potential is represented by the sum of the areas $1 \mathrm{I}$ and 1II), which is explained by the possibility of charging the HA during the non-operation period of the system (transition and standby modes).

At the same time, the HA potential exceeds the thermal needs necessary for the heating mode (the power deficit that the HA covers is represented by area 2).

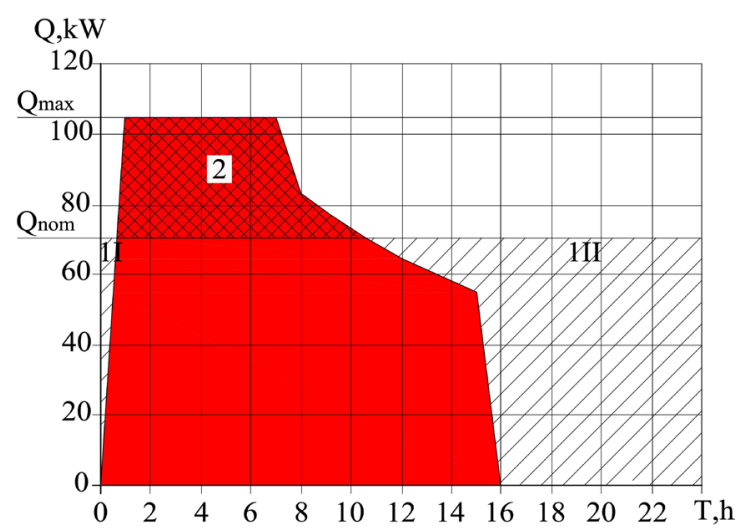

Fig. 2. Intermittent heating system load at $t_{e}=-18{ }^{\circ} \mathrm{C} ; T_{b}=200 \mathrm{~h}$, taking into account the HA possibility: 1 - potential of the heat generator (during the non-operation period) for the accumulation of heat; 2 - power shortage, which is covered by HA, where $T_{b}$ - the characteristic of the inertia of the building (time constant)

In this case, the intermittent heating system will operate with a minimum capacity of the heat generator (Fig. 3).

For example, using the graphoanalytical method, the minimum allowable thermal power of the heat generator of the object under study is established, equal to $Q_{\min }=53 \mathrm{~kW}$, and the required volume of the heat accumulator is $V_{H A}=19 \mathrm{~m}^{3}$ (Fig. 3, point A).

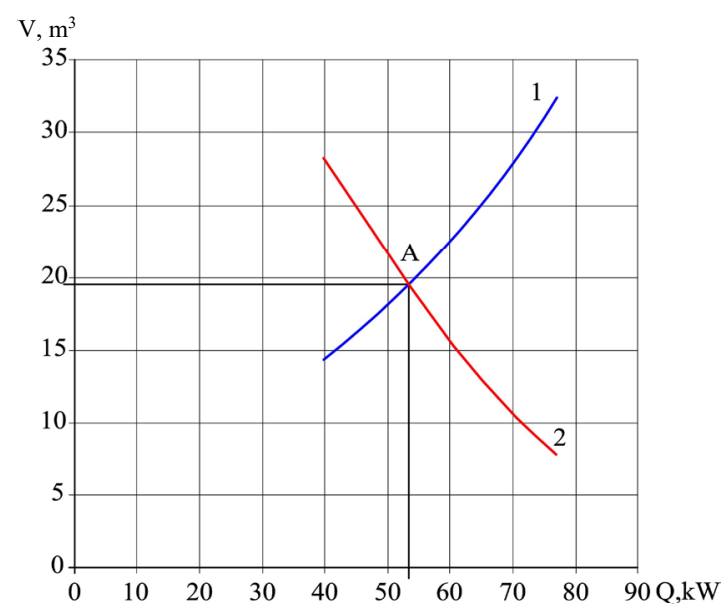

Fig. 3. The dependence of the HA $(V)$ volume on the power of the heat generator of the intermittent heating system $(Q)$ at $t_{e}=-18{ }^{\circ} \mathrm{C} ; T_{b}=200 \mathrm{~h}: 1-$ potential of the heat generator (during the non-operation period) for the accumulation of heat; 2 - power shortage is covered by HA

To summarize the results of numerical simulation of the intermittent heat supply system operating modes and the possibility of their distribution to other heat supply facilities, all the above absolute values (thermal power of the heat generator, HA thermal potential, HA volume) are presented in relative form (Fig. 4). 
The relative value of the reduction of thermal power is called the coefficient of thermal power reduction:

$$
k=Q / Q_{\max },
$$

where $Q_{\max }$ - the maximum power of the heat generator to ensure the heating mode during intermittent heat supply, $\mathrm{kW} ; Q$ - the current thermal power of the heat generator, $\mathrm{kW}$.

The physical content of the coefficient of reduction of thermal power $(k)$ is the degree of decrease in the thermal power of heat generators due to the use of the thermal potential of the heat accumulator.

To analyze the energy-saving capabilities of the heat accumulator of the system, a coefficient of efficiency of using the HA volume, capable of ensuring the heating mode, is proposed:

$$
\omega=V_{H A} / V_{\max },
$$

where $V_{H A}$ - HA volume, with the minimum allowable heat capacity of the system, $\mathrm{m}^{3} ; V_{\max }-$ the maximum HA volume available for use, which works with maximum thermal power, $\mathrm{m}^{3}$.

The coefficient of efficiency of using the HA $(\omega)$ volume - the ratio of the HA volume (capable of replacing excess thermal power in the heating mode) and the maximum HA volume (available when using the system with maximum thermal power).

A joint analysis of the graphs of the change in the function $\omega=f(k)$ shows (Fig. 4):

- change in the potential of the heat generator during the non-operation period for the accumulation of heat (Fig. 4, curve 2) - an ascending character;

- a change in the HA thermal potential to ensure the heating mode (Fig. 4, curve 1) - a downward character.

Point $\mathrm{A}$ at the intersection of curves 1 and 2 corresponds to the desired HA volume, which provides coverage for the thermal needs of the heating mode.

Point A, found by the graphoanalytical method, corresponds to the rational conditions for using the combined intermittent heat supply system, which works with the maximum power replacement parameter due to the HA use. The accumulating substitution parameter (ASP) of thermal power due to the HA use is denoted by $\delta_{A S P}$.

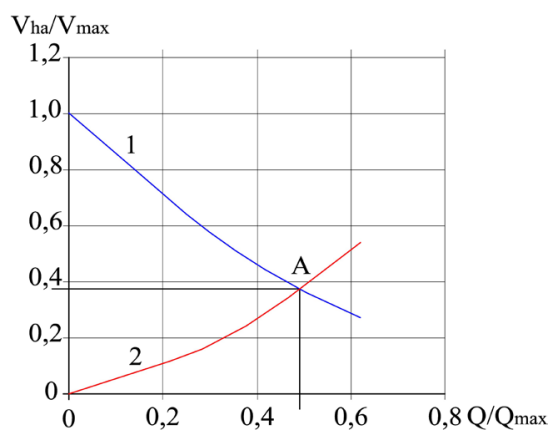

Fig. 4. The graph of the HA relative volume $\left(V_{H A} / V_{\max }\right)$ as a function of the coefficient of decrease in thermal power at $t_{e}=-18{ }^{\circ} \mathrm{C} ; T_{b}=200 \mathrm{~h}: 1$ - the potential of the heat generator (during the nonoperation period) for the heat accumulation; 2 - power shortage is covered by HA

The accumulating substitution parameter $\delta_{A S P}$ is the base for the selection of rational conditions for the use of a combined heat supply system. $\delta_{A S P}$ plays an essential role for putting into practice the principles of energy-saving technologies while providing heat for public buildings.

Thus, the results obtained (Fig. 3, 4) allow to solve an urgent problem - to establish the conditions for the rational functioning of the intermittent heat supply system, taking into account the parameter of the maximum displacement of the heat power of heat generators due to HA: 


$$
\delta_{A S P}=V_{H A}\left(Q_{\text {nom }}-Q_{\text {min }}\right), \mathrm{m}^{3} / \mathrm{kW},
$$

where $V_{H A}$ - the required volume of the heat accumulator, $\mathrm{m}^{3} ; Q_{\text {nom }}-$ the rated (calculated) thermal power of the source, $\mathrm{kW} ; Q_{\min }-$ the minimum allowable heat source, $\mathrm{kW}$.

For example, for the combined heat supply system of the ONPU educational building No. 10 (Fig. 3) with $V_{H A}=19 \mathrm{~m}^{3} ; Q_{\text {nom }}=70 \mathrm{~kW} ; Q_{\text {min }} 53 \mathrm{~kW} ; \delta_{A S P}=1.18 \mathrm{~m}^{3} / \mathrm{kW}$.

The physical meaning of the substitution parameter $\delta_{A S P}$ consists in the fact that it shows how much AK should be selected for the combined heat supply system in order to ensure the maximum replacement of the fraction of the thermal power of the system that operates in the heating mode.

Using the substitution parameter $\delta_{A S P}$, it is possible to determine the rational conditions for the operation of heat generators, which are characterized by a reduced thermal power of heat generators (Fig. 5).

A comparison of the circuit design features and energy efficiency of the combined heat supply system, taking into account the substitution parameter $\delta_{A S P}$, shows the advantages of this approach.

A comparison of the graphs in relation to the choice of the heat source, taking into account the influence of the $\delta_{A S P}$ parameter and without taking into account the influence of $\delta_{A S P}$ (Fig. 6, a, b), shows that when using heat accumulators, a significant energy-saving effect can be achieved (Fig. 6, $\boldsymbol{b}$ ) by substitution of a substantial part of the thermal power of heat generators due to HA.

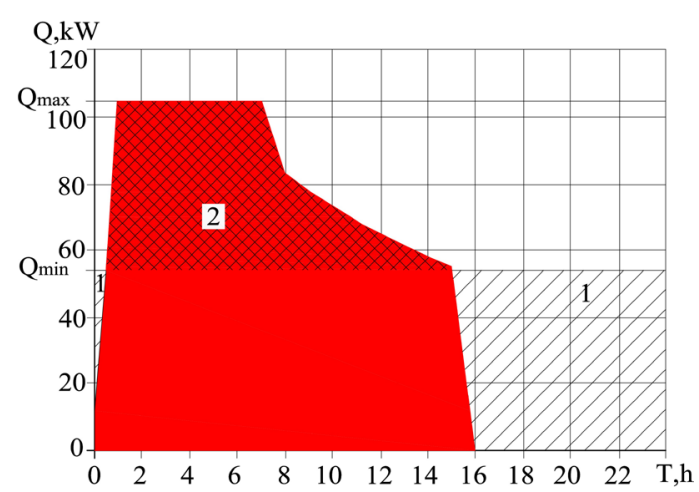

Fig. 5. The load of the heat supply system at $t_{e}=-18^{\circ} \mathrm{C} ; T_{b}=200 \mathrm{~h}, k=Q / Q_{\max }=0,49$ :

1 - the potential of the heat generator (during the non-operation period) for heat storage;

2 - power shortage, which is covered by HA
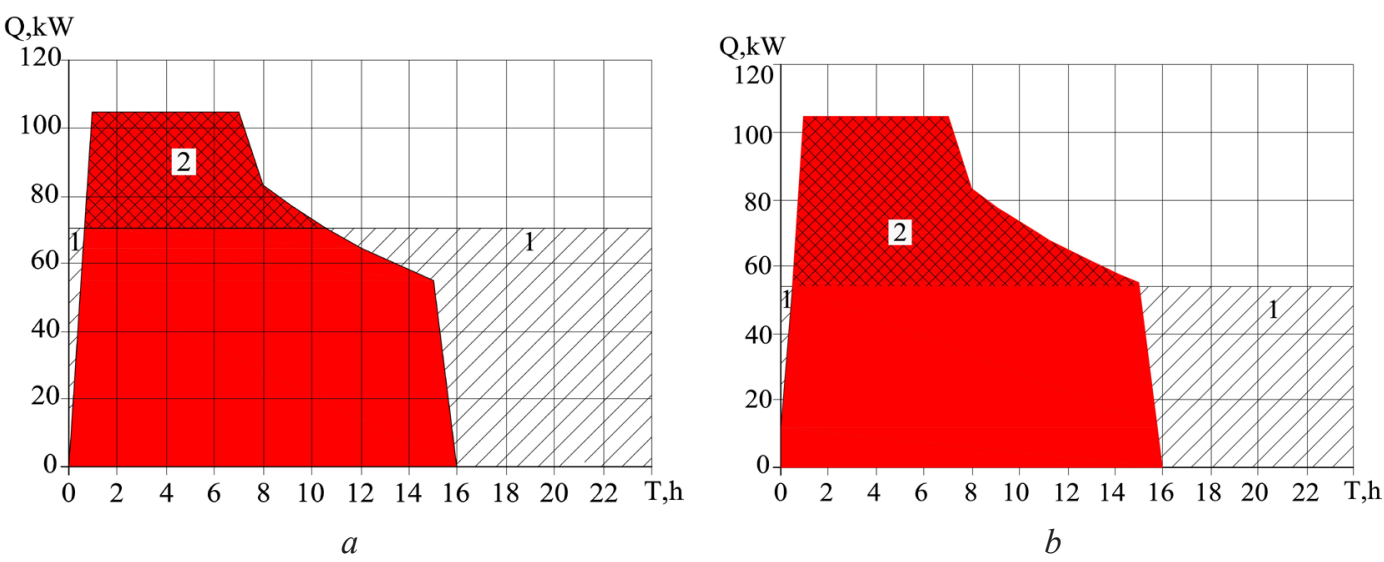

Fig. 6. The rationale for choosing the rational amount of heat accumulator: $a$ - without taking into account the substitution parameter; $b$ - taking into account the substitution parameter

In turn, by reducing the power of the heat generators of the intermittent heating system, it is possible to increase the operational life of the main and auxiliary equipment of the heat supply system. 
In addition, a decrease in the maximum power of the heat generators of the heat supply system reduces the lower level of power modulation, which reduces the number of starts of power equipment, which reduces the loss of energy by heat generators, that is, increases the park resource of the system.

\section{The results of modeling the dynamics of the heat supply system}

Analysis of the results of mathematical modeling shows that when using heat accumulators, the load curve of heat generators is substantially equalized, which leads to uniform operation of the heat source.

Moreover, the HA operation during the day is divided into three periods (Fig. 7):

- operation in the heating mode (area 1) together with HA (area 4);

- operation during the operation period (area 2);

- operation in the mode of accumulation of heat during the non-operation period (area 3 ).

With an increase in the degree of thermal modernization, for example, when using combined thermal insulation, the peak power of the heat generators decreases, which can lead to a decrease in the required volume of the heat accumulator and the minimum power of the source, respectively (Fig. 8, 9). The aforementioned is explained by a more forced mode of heating due to a decrease in heat losses due to heating of the building walls and a decrease in the required power reserve of the combined heat supply system (Fig. $9 \boldsymbol{a}, \boldsymbol{b})$.

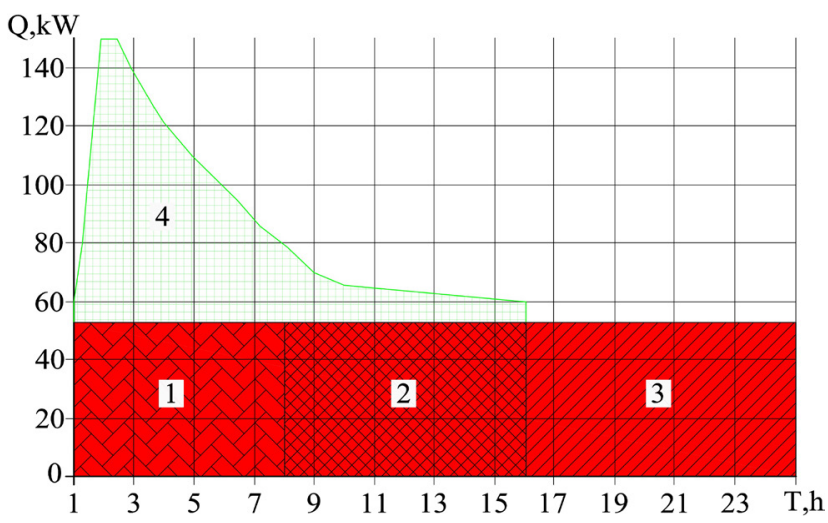

Fig. 7. The load of the heat supply system with HA at $t_{e}=-18^{\circ} \mathrm{C} ; T_{b}=200 \mathrm{~h}$,

1 - HA operation in the heating mode; 2 - HA operation in operating mode;

3 - HA operation during the non-operation period for charging the HA;

4 - HA operation in the heating mode and in the operating mode together with HA

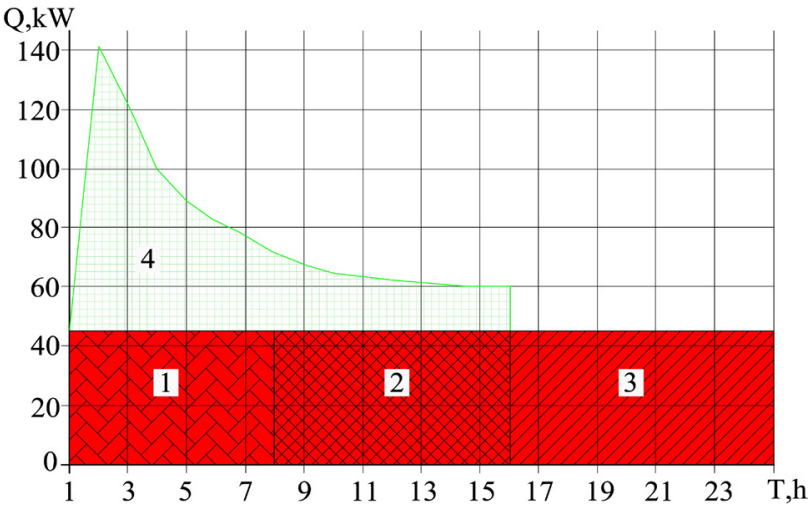

Fig. 8. The load of the heat supply system with HA at $t_{e}=-18{ }^{\circ} \mathrm{C} ; T_{b}=200 \mathrm{~h}$, with HA and using combined thermal insulation: 1 - HA operation in the heating mode;

2 - HA operation in operating mode; 3 - HA operation during the non-operation period at HA; $4-$ HA operation in the heating mode and in the operating mode 

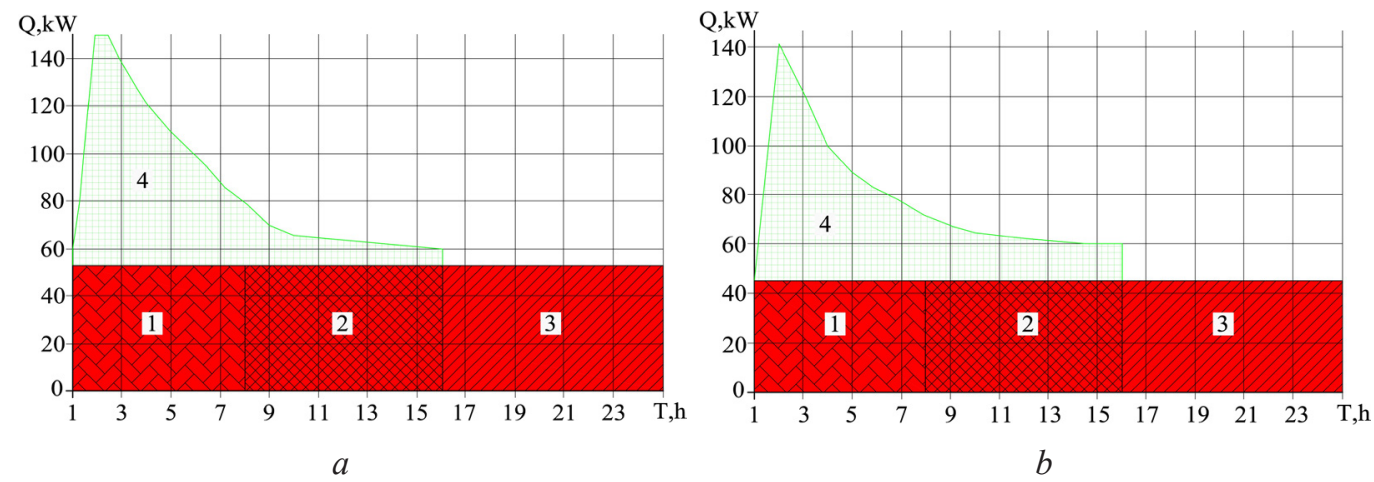

Fig. 9. Summarizing the results of numerical simulation of the heat supply system: $a$-without installing combined thermal insulation in the building;

$b$ - taking into account the device of combined thermal insulation in the building

\section{Discussion of the research results of the effectiveness of the use of heat accumulators in combined heat supply systems}

Thus, it is possible to conclude that the HA use is a way to significantly reduce the maximum power of heat generators due to the rational use of the HA energy potential, which corresponds to the principles of energy-saving technologies [19].

The next step in increasing the efficiency of using heat supply sources is to determine the minimum allowable power of heat generators. This value can be established by quantitative comparison of both influential parameters, namely, the HA thermal potential, which is charged during the non-operation period, and the excess heat, which ensures the heating mode [20].

Generalization and analysis of the results of numerical simulation allows to establish:

- the range of a possible decrease in the power of the heat generator due to its joint operation with the heat accumulator in the heating mode;

- justify the feasibility of using one degree or another of thermal modernization of the building (conditions for the use of combined thermal insulation, both external and internal);

- Pthe additional potential to reduce the power of heat generators $(\sim 14 \%)$ and HA volume $(\sim 5 \%)$ through the use of combined thermal insulation determines the level of thermal modernization. The use of shielding of internal walls in combined thermal insulation (reducing the total heat consumption for heating massive internal walls) allows to reduce the heating period and, accordingly, to reduce the power of the heat generator and the volume of the heat accumulator.

The solution of this problem will increase the feasibility of using a combined heat supply system using heat accumulators, the cost of which is reduced due to the rational redistribution of power between heat generators and HA.

\section{Conclusions}

Based on the results of numerical modeling, the features of the main operating modes of the combined heat supply system using heat accumulators are determined. The factors affecting the efficiency of the intermittent heat supply system are also identified, namely: the duration of the modes, the moments of switching from mode to mode, and also the case of refusal from standby operation modes.

To determine the possibility of replacing the thermal power of the heat generator, the $\delta_{A S P}$ parameter is proposed, which is the defining "accumulation substitution parameter", since it allows to choose rational conditions for using HA.

The results obtained allow to solve the problem of the effective functioning of the intermittent heat supply system with a maximum fraction of the replacement of the thermal power of the HA heat generator.

The application of the methodology for choosing the rational operation conditions of the combined heat supply system, taking into account the $\delta_{A S P}$ parameter, allows achieving a reduction in the maximum power of heat generators by $50 \%$. 


\section{References}

[1] Maliarenko, V. A. (2007). Shliakhy pidvyshchennia efektyvnosti komunalnoi enerhetyky. Integrirovannye tehnologii i energosberezhenie, 3, 3-14.

[2] Wang, Z., Luo, M., Geng, Y., Lin, B., Zhu, Y. (2018). A model to compare convective and radiant heating systems for intermittent space heating. Applied Energy, 215, 211-226. doi: https://doi.org/10.1016/j.apenergy.2018.01.088

[3] Gustafson, R. D., Hiibel, S. R., Childress, A. E. (2018). Membrane distillation driven by intermittent and variable-temperature waste heat: System arrangements for water production and heat storage. Desalination, 448, 49-59. doi: https://doi.org/10.1016/ j.desal.2018.09.017

[4] Wang, Y., Yang, S. (2018). Proposal and thermodynamic analysis of a combined open-cycle absorption heat pump and thermal desalination system driven by high-humidity exhaust gas. Desalination, 448, 93-102. doi: https://doi.org/10.1016/j.desal.2018.10.003

[5] Khoury, J., Mbayed, R., Salloum, G., Monmasson, E. (2014). Modeling of a hybrid domestic solar/electric water heater for hardware implementation. MELECON 2014 - 2014 17th IEEE Mediterranean Electrotechnical Conference. doi: https://doi.org/ 10.1109/melcon.2014.6820596

[6] Khoury, J., Mbayed, R., Salloum, G., Monmasson, E. (2015). Comparison of the water heating technique's impact on the sizing of a standalone PV-battery backup system assisting an intermittent primary energy source. IECON 2015 - 41st Annual Conference of the IEEE Industrial Electronics Society. doi: https://doi.org/10.1109/iecon.2015.7392206

[7] Morozyuk, L., Denysova, A., Alhemiri, S. A. (2019). Synthesize of the integrative trigeneration system for a «solar house» in the Middle East region. Eastern-European Journal of Enterprise Technologies, 1 (8 (97)), 43-50. doi: https://oi.org/10.15587/17294061.2019.156129

[8] Klymchuk, O., Denysova, A., Balasanian, G., Alhemiri, S. A., Borysenko, K. (2018). Implementation of an integrated system of intermittent heat supply for educational institutions. EUREKA: Physics and Engineering, 1, 3-11. doi: https://doi.org/ 10.21303/2461-4262.2018.00557

[9] Panferov, V. I., Anisimova, E. Yu. (2008). Analiz vozmozhnosti ekonomii teplovoy energii pri preryvistom rezhime otopleniya. Vestnik Yuzhno-Ural'skogo gosudarstvennogo universiteta. Seriya: Stroitel'stvo i arhitektura, 12, 30-37.

[10] Kutsenko, A. S., Kovalenko, S. V., Tovazhnyanskiy, V. I. (2014). Analiz energoeffektivnosti preryvistogo rezhima otopleniya zdaniya. Polzunovskiy vestnik, 1 (4), 247-253.

[11] Mazurenko, A., Denysova, A., Balasanian, G., Klimchuk, A., Borysenko, K. (2017). Improving the operation modes efficiency in heat pump systems of hot water supply with the two-stage heat accumulation. Eastern-European Journal of Enterprise Technologies, 1 (8 (85)), 27-33. doi: https://doi.org/10.15587/1729-4061.2017.92495

[12] Klymchuk, O., Denysova, A., Shramenko, A., Borysenko, K., Ivanova, L. (2019). Theoretical and experimental investigation of the efficiency of the use of heat-accumulating material for heat supply systems. EUREKA: Physics and Engineering, 3, 32-40. doi: https://doi.org/10.21303/2461-4262.2019.00901

[13] Morozyuk, L., Sokolovska-Yefymenko, V., Kandieieva, V., Moshkatiuk, A., Kukoliev, A. (2019). Thermodynamic analysis of the schemecycle design of a heatingcoolingmachinefor an individual house. Eastern-European Journal of Enterprise Technologies, 3 (8 (99)), 43-49. doi: https://doi.org/10.15587/1729-4061.2019.167101

[14] Mazurenko, A., Klimchuk, A., Yurkovsky, S., Omeko, R. (2015). Development of the scheme of combined heating system using seasonal storage of heat from solar plants. Eastern-European Journal of Enterprise Technologies, 1 (8 (73)), 15-20. doi: https://doi.org/10.15587/1729-4061.2015.36902

[15] Vasil'ev, G. P., Lichman, V. A., Peskov, N. V. (2010). Chislenniy metod optimizatsii preryvistogo rezhima otopleniya. Matematicheskoe modelirovanie, 22 (11), 123-130.

[16] Sorensen, B. (2011). Preobrazovanie, peredacha i akkumulirovanie energii. Dolgoprudniy: Izdatel'skiy Dom «Intellekt», 296.

[17] Korinchevska, T. V. (2010). Perspektyvni metody akumuliuvannia teplovoi enerhiyi. Naukovi pratsi ONAKhT, 37, $236-241$.

[18] Wu, C., Nikulshin, V. (2000). Method of thermoeconomical optimization of energy intensive systems with linear structure on graphs. International Journal of Energy Research, 24 (7), 615-623. doi: https://doi.org/10.1002/1099-114x(20000610)24:7<615:: aid-er608>3.0.co;2-p

[19] Matsevity, Yu. M., Ganja, N. G., Khimenko, A. V. (2011). Evaluation of energy efficiency of systems electric thermal storage heating of civil buildings. Energosberezhenie. Energetika. Energoaudit, 10, 9-16.

[20] Ganzha, A. M., Zaiets, O. M., Marchenko, N. A., Kollarov, O. Ju., Njemcev, E. M. (2018). Methodology of calculation of multiplex heat exchang apparatus with cross flow and mixing in heat carriers. Journal of new technologies in environmental science, 2 (1), 26-35. 